\title{
Trends in disciplines selected by applicants in the Canadian resident matches, 1994-2004
}

W e reviewed data collected by the Canadian Resident Matching Service from 1994 to 2004 to study trends in applicants' preferences for disciplines. An applicant's ranking of a specialty as his or her first choice was used as a marker of preference. The data were cross-tabulated by specialty and year for men and women and for both sexes combined. Disciplines with fewer than 5 applicants in any cell were combined to form an "other" category. Trends were described as the proportion of applicants selecting each specialty as a first choice as well as the ratio of the number of first choices to the quota of positions offered each year.

We observed significant changes in preference for 2 specialties: anesthesia showed an increase in popularity and family medicine a decrease.

For anesthesia, the proportion of applicants who selected this specialty as their first choice rose, from $3.9 \%(n=51)$ in 1994 to $5.4 \%(n=70)$ in 2004 . The number of positions remained relatively stable (65 in 1994 and 70 in 2004), yet the ratio of first-choice applicants to the quota of positions available increased, from 0.78 in 1994 to 1.0 in 2004 (Fig. 1, top). Separate analyses by sex revealed that this trend was significant for male applicants but not for females. Concurrent with these increases, the number of unmatched anesthesia positions after the first round of the match o decreased from 10 in 1994 to 6 in 2004.

For family medicine, the proportion of applicants who selected this specialty as their first choice decreased, from $32.4 \%(n=423)$ in 1994 to $26.4 \%(n=339)$ in 2004. The ratio of first-choice applicants to quota of positions offered also decreased, from 0.83 in 1994 to 0.64 in 2004 (Fig. 1, bottom). Separate analyses by sex again revealed that this trend was statistically significant for male applicants but not females. During the period studied, the number of unmatched family medicine positions after the first round of the match increased from 20 in 1994 to 124 in 2004.

In the post-match survey administered each year, applicants were asked to select from a list the factors that influenced their choice. For both male and female applicants and for all first-choice disciplines, commonly cited factors were role models, students' experiences with patients in the clinical setting, the type of problems patients presented and career satisfaction of preceptors. Procedural skills were commonly cited as an influential factor by candidates applying to surgical disciplines. Predictable work hours and a reasonable lifestyle were most frequently chosen by those applying to anesthesia and radiology. ${ }^{1}$

Between 1994 and 2004, most undergraduate medical programs introduced mandatory rotations in both anesthesia and family medicine. Although exposure to a discipline is necessary for informed decision-making, it alone does not seem to be sufficient to generate an increase in popularity.

Reasons for the observed trends are likely multifactorial and cannot be elucidated from these data alone. Still, program directors of specialties seeing a decline in popularity may need to address factors that appear to influence applicants' decisions to choose the more popular specialties. Solutions for in-

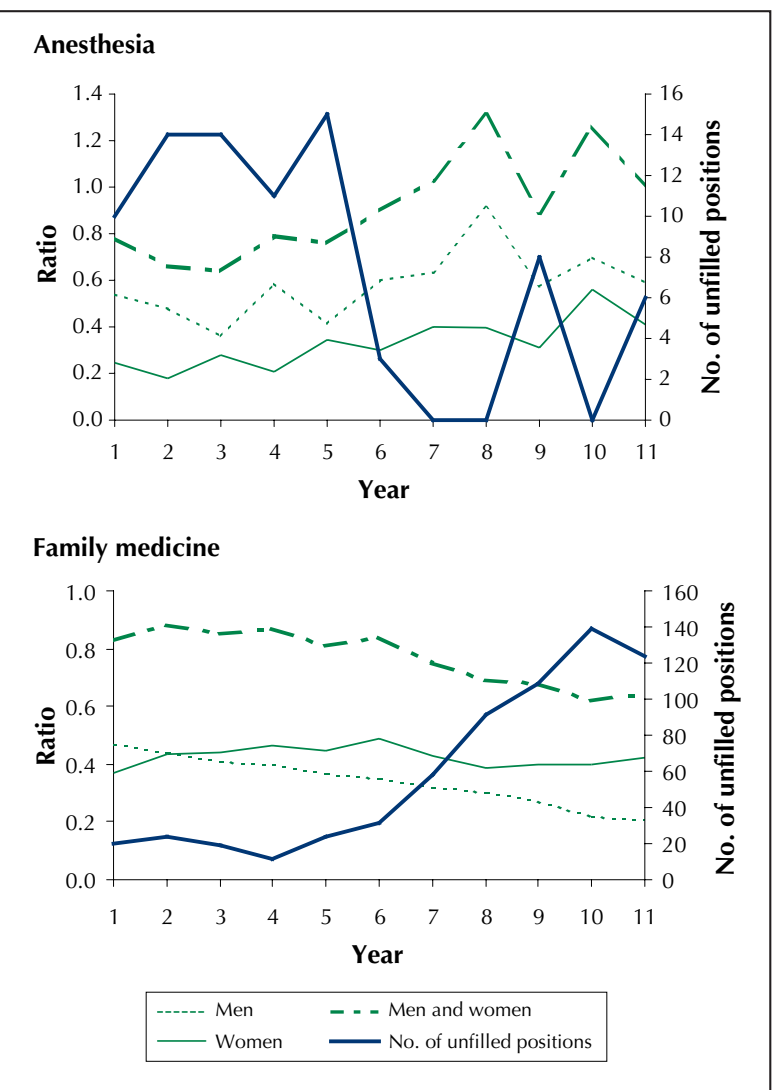

Fig. 1: Ratio of first choice of applicants to quota of positions offered each year, and number of unfilled positions after the first round of the match, for anesthesia and family medicine from 1994 to 2004 .

creasing the number of highquality applicants to less popular programs may need to go beyond the training period and critically address the practice environment.

\section{Adrian Harvey}

Jean-Gaston DesCôteaux

Faculty of Medicine

University of Calgary

Calgary, Alta.

Sandra Banner

Canadian Resident Matching Service Ottawa, Ont.

\section{Reference}

1. Yang H, Wilson-Yang K, Raymer K. Recruitment in anaesthesia: results of two national surveys. Can 7 Anaesth 1994;41(7):621-7. 